\title{
Cervical spinal cord bullet fragment removal using a minimally invasive surgical approach: a case report
}

\author{
Cort D Lawton ${ }^{1}$, Zachary A Smith ${ }^{1 *}$, Koichi Sugimoto ${ }^{1}$, Justin S Smith ${ }^{2}$ and Richard G Fessler ${ }^{1}$
}

\begin{abstract}
Introduction: We present a case of penetrating gunshot injury to the high-cervical spinal cord and describe a minimally invasive approach used for removal of the bullet fragment. We present this report to demonstrate technical feasibility of a minimally invasive approach to projectile removal.

Case presentation: An 18-year-old African-American man presented to our hospital with a penetrating gunshot injury to the high-cervical spine. The bullet lodged in the spinal cord at the C1 level and rendered our patient quadriplegic and dependent on a ventilator. For personal and forensic reasons, our patient and his family requested removal of the bullet fragment almost one year following the injury. Given the significant comorbidity associated with quadriplegia and ventilator dependency, a minimally invasive approach was used to limit the peri-operative complication risk and expedite recovery. Using a minimally invasive expandable retractor system and the aid of a microscope, the posterior arch of C1 was removed, the dura was opened, and the bullet fragment was successfully removed from the spinal cord.
\end{abstract}

Conclusions: Here we describe a minimally invasive procedure demonstrating the technical feasibility of removing an intramedullary foreign object from the high-cervical spine. We do not suggest that the availability of minimally invasive procedures should lower the threshold or expand the indications for the removal of bullet fragments in the spinal canal. Rather, our objective is to expand the indications for minimally invasive procedures in an effort to reduce the morbidity and mortality associated with spinal procedures. In addition, this report may help to highlight the feasibility of this approach.

Keywords: Bullet, Gunshot wound, Intramedullary, Minimally invasive spine surgery, Spinal cord

\section{Introduction}

Gunshot injury to the spine accounts for $13 \%$ to $17 \%$ of all spinal cord injuries annually [1]. Spinal cord decompression and bullet removal remain controversial and can be associated with a high rate of complications [1-5]. Minimally invasive (MI) approaches have been applied to multiple spinal pathologies, including degenerative, traumatic, and neoplastic, in order to decrease morbidity and expedite recovery [6-13]. We present the case of a ventilator-dependent quadriplegic patient, who presented 11 months following a gunshot wound,

\footnotetext{
*Correspondence: zsmithmd@gmail.com

'Department of Neurological Surgery, Northwestern University, 676 N. St. Clair Street, Suite 2210, Chicago, IL 60661, USA

Full list of author information is available at the end of the article
}

requesting removal of the bullet fragment from the high-cervical spinal cord. We describe the use of a muscle splitting, MI approach to successfully remove the fragment from the spinal cord at the $\mathrm{C} 1$ level.

\section{Case presentation}

A previously healthy 18-year-old African-American man suffered a high-cervical gunshot wound to the neck while driving. This injury resulted in quadriplegia at the $\mathrm{C} 2$ sensory level and ventilator dependence. Imaging studies demonstrated a retained bullet fragment in the spinal canal at the level of $\mathrm{C} 1$ (Figure 1A,B). His initial care was received at another medical center where he was evaluated. No surgical intervention for the gunshot wound was pursued. He was ultimately discharged to a rehabilitation center after a tracheostomy was performed

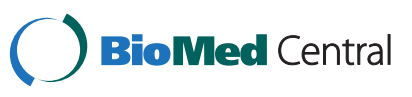




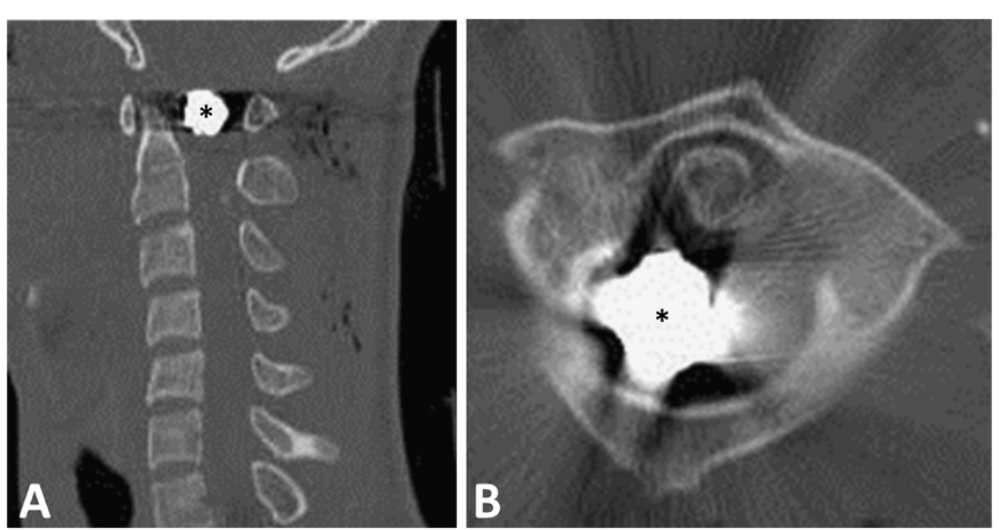

Figure 1 Radiographic imaging of a retained bullet fragment in the high-cervical spine. Sagittal (A) and axial (B) computed tomography (CT) images show the relationship of the fragment (designated by *) to the arch of $\mathrm{Cl}$ and the dens of $\mathrm{C} 2$. Note the fracture of the right posterior arch of C1 (arrow).

and a gastrostomy tube and inferior vena cava (IVC) filter were placed. His recovery was complicated by cardiac arrest, with successful resuscitation, and pneumonia.

Our patient and his family presented to our clinic 11 months after the injury seeking removal of the bullet fragment for personal and forensic reasons. $\mathrm{He}$ remained without neurologic improvement, and the family was clearly counseled that such a procedure would be extremely unlikely to result in any neurological recovery.

After induction of general anesthesia, a Mayfield head frame was placed, and our patient was turned to a prone position on a standard operative table with a Wilson frame. The head frame was secured to the operative table, and the wound was prepared and draped in a sterile fashion. Fluoroscopy was used to determine the bullet location. An approximately $5 \mathrm{~cm}$ midline longitudinal incision was created, centered over the level of the bullet fragment. Under fluoroscopic guidance, the METRx $x^{\mathrm{Tm}} \mathrm{X}$ Tube Retraction System (Medtronic Sofamor Danek, Minneapolis, MN, USA) was placed, with sequential dilation of the muscle and exposure of the posterior arch of $\mathrm{C} 1$. The retractor was secured to the operative table and expanded to a working diameter of approximately $5 \mathrm{~cm}$. An operative microscope was then brought into the field for visualization. The posterior arch of $\mathrm{C} 1$ was removed using a Kerrison \#2 bone punch, and the underlying dura was exposed. The dura was incised and found to be remarkably adherent to an underlying mass of granulation tissue. Rhoton ${ }^{\text {tw }}$ microdissectors were used to carefully dissect the granulation tissue and expose the bullet fragment. The fragment was dissected free from the surrounding granulation tissue and removed (Figure 2A). The dura was closed using a running 5-0 prolene suture and a custom needle driver and knot pusher (Scanlan International, Saint Paul, MN, USA). The wound was closed using deep and subcutaneous absorbable interrupted sutures, and the skin surface was covered with surgical glue.

The surgical time was approximately two hours and 20 minutes, and the estimated blood loss was $50 \mathrm{~cm}^{3}$. The procedure and hospital stay were uncomplicated. At a 6month follow-up, our patient remained at his preoperative neurologic baseline and free from evidence of complications with only a small scar from the site of skin incision and bullet penetration (Figure 2B).

\section{Discussion}

There are few absolute indications for the removal of a bullet lodged in the spinal canal, including neurological deterioration, infection, and lead or copper toxicity [2]. Whether to perform such a procedure in situations outside of these indications remains controversial. We present a case where a quadriplegic, ventilatordependent patient requested removal of a bullet fragment retained in the high-cervical spinal cord. Given the comorbidity generally associated with ventilatordependent quadriplegia, exemplified by our patient's own history of cardiac arrest and pneumonia, we sought to minimize the morbidity of the planned procedure. Further, it should be noted that many patients who present following a high-velocity penetrating trauma are commonly medically unstable. In these situations, a minimally invasive approach of this nature may be advantageous given that a larger, open operation may be medically contraindicated.

Standard open approaches for removal of bullet fragments from the spinal canal have been associated with a high rate of complications. Simpson et al. retrospectively reviewed 160 cases of penetrating spinal injury, including 142 cases of gunshot wounds and 18 stab wounds [14]. Complications included meningitis, cerebrospinal fluid leakage, and wound infections. The complication rate was considerably higher in the patients who were 

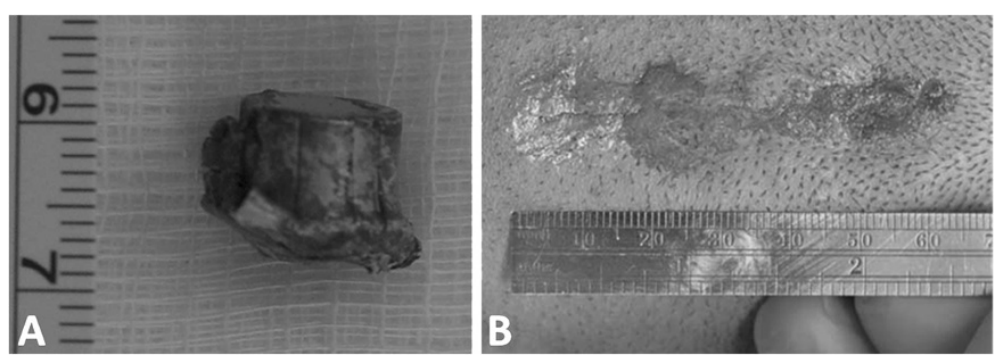

Figure 2 (A) Photograph of the extracted bullet fragment and (B) photograph of our patient's neck in the prone position, demonstrating the post-operative skin incision and the site of bullet penetration.

surgically treated (22\%) compared with patients who were treated non-surgically (7\%). Minimally invasive procedures to access the spine have been developed in order to reduce approach-related morbidity and/or postoperative complications [6,9,10]. Initial applications were primarily confined to discectomies and decompressions for degenerative spine disease, [6,8,10,11,15,16] but with recognition of the benefits and further advances in technology, the potential indications have markedly expanded [12,13,17-19]. The ability to safely and effectively access the spinal intradural compartment through a MI approach has been reported $[7,12]$. In addition, the removal of bullet fragments in the lumbar spine has also been previously discussed $[20,21]$.

When contemplating removal of a retained bullet fragment in the spinal canal, it is important that the indications and expectations are clear. These injuries are often treated non-operatively, especially in cases of complete neurological deficit. However, in select circumstance, when surgery is elected, a minimally invasive approach may be both safe and feasible.

\section{Conclusions}

Here, we have demonstrated the technical feasibility of removing an intramedullary foreign object from the high-cervical region. Although surgical indications remain controversial, removal of a foreign object, such as a bullet fragment, from the high-cervical spinal cord may be safely and effectively achieved through a MI approach.

\section{Consent}

Written informed consent was obtained from the patient for publication of this manuscript and any accompanying images. A copy of the written consent is available for review by the Editor-in-Chief of this journal.

\section{Competing interests}

Zachary A. Smith's contributions were supported by the CNS Spine

Fellowship Award and the AANS/CNS Spine Section Apfelbaum Grants.

\section{Authors' contributions}

CDL was a major contributor in writing the manuscript, provided critical revisions, and created the figures. ZAS provided critical revisions and contributed to the writing, concept, design, revision, and completion of the manuscript. KS was a significant contributor to the writing of this manuscript. JSS was a contributor in writing the manuscript, the conception, and the design. RGF provided critical revisions and gave the final approval of the version to be published. All the contributing authors have read and approved the final manuscript.

\section{Author details}

'Department of Neurological Surgery, Northwestern University, 676 N. St. Clair Street, Suite 2210, Chicago, IL 60661, USA. ${ }^{2}$ Neurological Surgery, UVA Spine Center, 415 Ray C. Hunt Dr., Charlottesville, VA 22903, USA.

Received: 19 January 2012 Accepted: 9 May 2012

Published: 9 August 2012

\section{References}

1. Bono CM, Heary RF: Gunshot wounds to the spine. Spine J 2004, 4:230-240.

2. Tindel NL, Marcillo AE, Tay BK, Bunge RP, Eismont FJ: The effect of surgically implanted bullet fragments on the spinal cord in a rabbit model. J Bone Joint Surg Am 2001, 83:A:884-A:890.

3. Kahraman S, Gonul E, Kayali H, Sirin S, Duz B, Beduk A, Timurkaynak E: Retrospective analysis of spinal missile injuries. Neurosurg Rev 2004, 27:42-45.

4. Waters RL, Sie IH: Spinal cord injuries from gunshot wounds to the spine. Clin Orthop Relat Res 2003, 408:120-125.

5. Waters RL, Adkins RH: The effects of removal of bullet fragments retained in the spinal canal. A collaborative study by the National Spinal Cord Injury Model Systems. Spine 1991, 16:934-939.

6. Fessler RG, Khoo LT: Minimally invasive cervical microendoscopic foraminotomy: an initial clinical experience. Neurosurgery 2002, 51:S37-S45.

7. Gala VC, Voyadzis JM, Burkes A, Fessler RG: Outcomes following minimally invasive resection of intradural-extramedullary spinal tumors. http://2007. cns.org/AbstractPop2.aspx?!D=1318.

8. Isaacs RE, Podichetty VK, Sandhu FA, Santiago P, Spears JD, Aaronson O, Kelly K, Hrubes M, Fessler RG: Thoracic microendoscopic discectomy: a human cadaver study. Spine 2005, 30:1226-1231.

9. Isaacs RE, Podichetty VK, Santiago P, Sandhu FA, Spears J, Kelly K, Rice L, Fessler RG: Minimally invasive microendoscopy-assisted transforaminal lumbar interbody fusion with instrumentation. J Neurosurg Spine 2005, 3:98-105.

10. Khoo LT, Fessler RG: Microendoscopic decompressive laminotomy for the treatment of lumbar stenosis. Neurosurgeny 2002, 51:S146-S154.

11. Le H, Sandhu FA, Fessler RG: Clinical outcomes after minimal-access surgery for recurrent lumbar disc herniation. Neurosurg Focus 2003, 15:E12.

12. Ogden AT, Fessler RG: Minimally invasive resection of intramedullary ependymoma: a case report and literature review. Neurosurgery 2009, 65:E1203-E1204. 
13. Tredway TL, Santiago P, Hrubes MR, Song JK, Christie SD, Fessler RG: Minimally invasive resection of intradural-extramedullary spinal neoplasms. Neurosurgery 2006, 58:ONS52-ONS58.

14. Simpson RK Jr, Venger BH, Narayan RK: Treatment of acute penetrating injuries of the spine: a retrospective analysis. J Trauma 1989, 29:42-46.

15. Perez-Cruet MJ, Foley KT, Isaacs RE, Rice-Wyllie L, Wellington R, Smith MM, Fessler RG: Microendoscopic lumbar discectomy: technical note. Neurosurgery 2002, 51:S129-S136.

16. Rosen DS, OToole JE, Eichholz KM, Hrubes M, Huo D, Sandhu FA, Fessler RG: Minimally invasive lumbar spinal decompression in the elderly: outcomes of 50 patients aged 75years and older. Neurosurgery 2007 60:503-509.

17. Hsieh PC, Koski TR, Sciubba DM, Moller DJ, O'Shaughnessy BA, Li KW Gokaslan ZL, Ondra SL, Fessler RG, Liu JC: Maximizing the potential of minimally invasive spine surgery in complex spinal disorders. Neurosurg Focus 2008, 25:E19.

18. Ogden AT, Eichholz K, OToole J, Smith JS, Gala V, Voyadzis JM, Sugimoto K Song J, Fessler RG: Cadaveric evaluation of minimally invasive posterolateral thoracic corpectomy: a comparison of 3 approaches. J Spinal Disord Tech 2009, 22:524-529.

19. Smith JS, Ogden AT, Fessler RG: Minimally invasive posterior thoracic fusion. Neurosurg Focus 2008, 25:E9.

20. Vasudevan RR, Galvan G, Pait GT, Villavicencio AT, Bulsara KR: Muscle splitting approach with METRx ${ }^{\text {TM }}$ system for removal of intrathecal bullet fragment: a case report. J Trauma 2007, 62:1290-1291.

21. Tumialan LM, Walkup RR, Gupta SK: Minimally invasive retrieval of a bullet from the L5-S1 neural foramina after transperitoneal gunshot wound. Spine J 2009, 9:169-173.

doi:10.1186/1752-1947-6-235

Cite this article as: Lawton et al:: Cervical spinal cord bullet fragment removal using a minimally invasive surgical approach:

a case report. Journal of Medical Case Reports 2012 6:235.

\section{Submit your next manuscript to BioMed Central and take full advantage of:}

- Convenient online submission

- Thorough peer review

- No space constraints or color figure charges

- Immediate publication on acceptance

- Inclusion in PubMed, CAS, Scopus and Google Scholar

- Research which is freely available for redistribution 